\title{
Dry eye in the COVID-19 era: how the measures for controlling pandemic might harm ocular surface
}

\author{
Giuseppe Giannaccare $^{1}$ (D) Sabrina Vaccaro ${ }^{1} \cdot$ Alessandra Mancini $^{1} \cdot$ Vincenzo Scorcia $^{1}$
}

Received: 8 June 2020 / Revised: 12 June 2020 / Accepted: 16 June 2020 / Published online: 19 June 2020

(C) Springer-Verlag GmbH Germany, part of Springer Nature 2020

\section{Dear Editor,}

The novel coronavirus (COVID-19) has quickly spread all over the world, and the number of cases and deaths is continuously growing. Since there is no currently available vaccine or therapy, unprecedented public health measures of home confinement including smart schooling/working as well as the mass use of face masks have been imposed in order to reduce the size of the outbreak [1]. Although we believe that these measures are essential for controlling pandemic, we would like to discuss about their potential impact on the health of ocular surface. In particular, we have identified two main mechanisms that could be responsible for the onset and/or worsening of dry eye disease (DED) symptoms.

On one hand, the increase in smart schooling/working exposes individuals to a higher use of visual display terminal (VDT) that is a well-known risk factor for DED [2]. The excessive evaporation of tear fluid attributable to prolonged blinking intervals while gazing is thought to be the main causative factor.

On the other hand, the mass use of face mask could represent an additional piece of the complex puzzle of DED in the COVID-19 era. In fact, the displacement of the mask or its incorrect fitting could disperse air around the eyes, and the air leaking could cause a rapid evaporation of tears. This scenario is similar to that one described in the setting of continuous positive airway pressure (CPAP) users but to a lesser extent. In fact, it is known that CPAP therapy increases ocular

Giuseppe Giannaccare

giuseppe.giannaccare@gmail.com

1 Department of Ophthalmology, University Magna Græcia of Catanzaro, Viale Europa, 88100 Catanzaro, Germaneto, Italy irritation, tear evaporation, and squamous metaplasia in the conjunctiva [3].

In order to investigate the prevalence of ocular discomfort symptoms pertaining to DED during COVID-19 pandemic, we administered a survey titled "COVID-19" to 200 randomly selected students attending the Faculty of Medicine of the University Magna Græcia (Catanzaro, Italy). Ethics approval for this study was obtained from the local Institutional Review Board.

Of the 200 surveys we attempted to deliver, 107 were returned with success. Respondents had a mean age of 28.5 years and 69 of them $(64.5 \%)$ were female. Twenty-six (24.3\%) used VDT in the last month for $>6 \mathrm{~h}$ daily, while 72 $(67.3 \%)$ wore face mask $>6$ h daily (Fig. 1 A-B).

Eleven subjects (10.3\%) described appearance or worsening of ocular discomfort symptoms, and 21 (19.6\%) reported the need for daily use of tear substitutes. The mean score of Ocular Surface Disease Index was 21, and 61 subjects (57\%) scored $\geq 15$ (pathological values) [4].

It has been shown that ocular symptoms including dry eye are relatively common among COVID-19 patients and can appear before the onset of respiratory symptomatology $[5$, 6]. There are emerging concerns that also the measures for controlling COVID-19 outbreak could determine detrimental effects on ocular surface. Our survey administered to healthy students exposed to both the risk factors for DED related to anti-pandemic measures (intense VDT use and face mask wearing) showed that a significant proportion experienced the onset of ocular discomfort symptoms that required the use of tear substitutes. Considering the difficulty of predicting the duration of the anti-pandemic measures, a longitudinal examination of DED signs and symptoms in healthy subjects and DED patients is desirable to evaluate the long-term impact of these measures on ocular surface. In the meantime, awareness among ophthalmologists of ocular surface diseases 

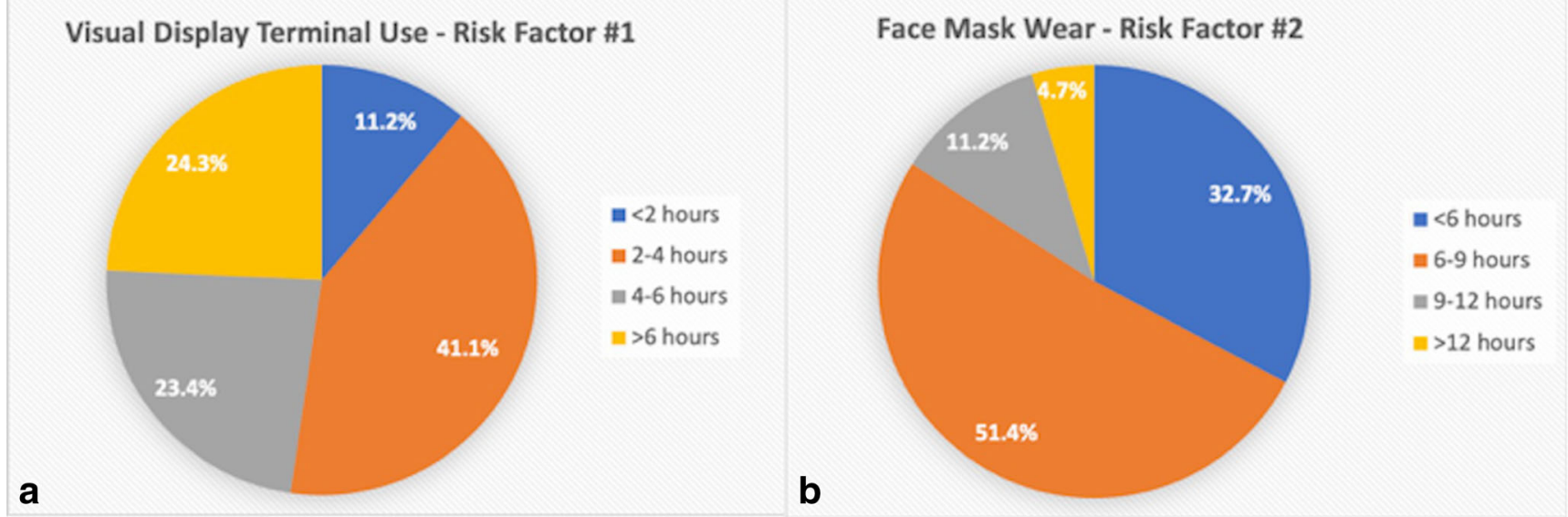

Fig. 1 Pie chart showing the distribution of the individuals who completed the survey according to the amount of time spent using visual display terminal (Part A) and wearing face mask (Part B)

associated with anti-COVID-19 measures should be spread. Furthermore, individuals exposed to increased screen time should be instructed to blink more often, while those who wear face mask to avoid its displacement or incorrect fitting that contribute to air leaking and ocular dryness.

Acknowledgments We would like to thank all the students that took the time to complete the survey.

\section{Compliance with ethical standards}

Conflict of interest The authors declare that they have no conflict of interest.

Informed consent Informed consent was obtained from all individual participants included in the study.

Ethical approval Ethics approval for this study was obtained from the local Institutional Review Board.

\section{References}

1. Pellegrini M, Bernabei F, Scorcia V, Giannaccare G (2020) May home confinement during the COVID-19 outbreak worsen the global burden of myopia? Graefes Arch Clin Exp Ophthalmol. https://doi. org/10.1007/s00417-020-04728-2

2. Uchino M, Yokoi N, Uchino Y, Dogru M, Kawashima M, Komuro A, Sonomura Y, Kato H, Kinoshita S, Schaumberg DA, Tsubota K (2013) Prevalence of dry eye disease and its risk factors in visual display terminal users: the Osaka study. Am J Ophthalmol 156:759 766. https://doi.org/10.1016/j.ajo.2013.05.040

3. Hayirci E, Yagci A, Palamar M, Basoglu OK, Veral A (2012) The effect of continous positive airway pressure treatment for obstructive sleep apnea syndrome on the ocular surface. Cornea 31:604-608. https://doi.org/10.1097/ICO.0b013e31824a2040

4. McAlinden C, Gao R, Wang Q, Zhu S, Yang J, Yu A, Bron AJ, Huang J (2017) Rasch analysis of three dry eye questionnaires and correlates with objective clinical tests. Ocul Surf 15:202-210. https:// doi.org/10.1016/j.jtos.2017.01.005

5. Hong N, Yu W, Xia J, Shen Y, Yap M, Han W (2020) Evaluation of ocular symptoms and tropism of SARS-CoV-2 in patients confirmed with COVID-19. Acta Ophthalmol. https://doi.org/10.1111/aos. 14445

6. Chen L, Deng C, Chen X, Zhang X, Chen B, Yu H, Qin Y, Xiao K, Zhang H, Sun X (2020) Ocular manifestations and clinical characteristics of 535 cases of COVID-19 in Wuhan, China: a crosssectional study. Acta Ophthalmol. https://doi.org/10.1111/aos.14472

Publisher's note Springer Nature remains neutral with regard to jurisdictional claims in published maps and institutional affiliations. 